\title{
To What Extent the Educational Engineering Program at a Private Lebanese University Prepares Students for the Workplace
}

\author{
Najwa Saba ‘Ayon, Yasmine Abu Adla, Raneem Zarafa \\ English Department, Rafik Hariri University, Meshref, Lebanon \\ Email: faresns@rhu.edu.lb, abouadlaya@students.rhu.edu.lb,zarafarm@students.rhu.edu.lb
}

How to cite this paper: 'Ayon, N. S., Adla, Y. A., \& Zarafa, R. (2019). To What Extent the Educational Engineering Program at a Private Lebanese University Prepares Students for the Workplace. Creative Education, 10, 1635-1652.

https://doi.org/10.4236/ce.2019.107117

Received: May 29, 2019

Accepted: July 23, 2019

Published: July 26, 2019

Copyright ( 2019 by author(s) and Scientific Research Publishing Inc. This work is licensed under the Creative Commons Attribution International License (CC BY 4.0).

http://creativecommons.org/licenses/by/4.0/

\begin{abstract}
Having well-prepared engineering graduates for the workplace has been of great importance in the last few decades (Warsame, 2017; Anastasiu, Anastasiu, Dumitran, Crizboi, Holmaghi, \& Roman, 2017; Pan, 2014). However, engineering graduates and trainees of a private Lebanese university seem to face difficulties during their training and in the workplace. Furthermore, little research has been done on this university's engineering educational program. Therefore, the aim of this research was to investigate the extent to which the engineering educational program at a private Lebanese university is preparing its students for the workplace. A mixed-methods design and different data collection instruments were used in this research study. A purposive sample of a hundred graduates and trainees of different engineering majors were surveyed. Additionally, six personal interviews were held with three graduates and three trainees of diverse engineering majors. The quantitative data collected were analyzed using Excel while the qualitative data were thematically analyzed. The collected quantitative and qualitative data were triangulated, and a lot of commonalities between them were detected. In fact, the findings revealed that most respondents reported that neither their lab nor their theoretical courses fully prepared them for the workplace. Nevertheless, most participants stated that their internship experience enhanced both their practical and soft skills. Appropriate recommendations such as encouraging instructors to include real-life case studies to enhance students' problem-solving skills and adding up-to-date equipment to the labs, were suggested to improve the engineering educational program at this private Lebanese university so that it can help its engineering graduates better survive in the workplace.
\end{abstract}

\section{Keywords}

Engineering Program, Educational System, Training Program, Internship, 


\section{Introduction}

One of the main objectives of undergraduate programs in general is to equip students with the necessary skills and competencies to thrive efficiently in the workplace (Warsame, 2017). This should apply to undergraduate engineering programs that are expected to arm their students with theoretical knowledge, practical experience, interpersonal skills, and sufficient training to meet the ever-growing demands of the workforce. Accordingly, the engineering program at any university is expected to offer its engineering students the proper educational program and internship experience to meet the needs of the workplace.

Despite the fact that engineers are supposed to be equipped with necessary skills in the workplace, it was found that universities are falling short when it comes to practical, fundamental, and training programs (Warsame, 2017). To illustrate, $55 \%$ of the surveyed engineering graduates in Romania stated that the needed competencies and skills were acquired at the workplace and not during their undergraduate studies (Anastasiu et al., 2017). Another study showed that only $20 \%$ of engineering graduates in New York were satisfied with the skills achieved in college after going into the workforce (Mckinsey, 2014 as cited in Anastasiu et al., 2017). Moreover, only $34 \%$ of managers were content with engineers coming from different colleges (Pearson Education and Skill Survey Program, 2015 as cited in Anastasiu et al., 2017).

Furthermore, Regev, Gause, and Wegmann (2008) stated that the current engineering curriculum is not student-centered; that is, it does not address diverse students' learning needs. Warsame (2017) reported that engineering instructors mainly use lecturing followed by assignments and assessments that are not sufficient to provide a solid background for students in the workplace. In addition, newly hired engineers struggle in the workplace due to insufficiently acquired problem-solving skills during their undergraduate studies (Warsame, 2017).

Similarly, other researchers complained about the inadequacy of engineering educational programs. For example, Ambrose (2013 as cited in Warsame, 2017) found that engineering graduates are utilizing an on-the-job autodidactic approach to complete required projects. Furthermore, according to Elahinia and Ciocanel (2008), engineering labs are now constructed in such a way that students are required to complete a task rather than solve a problem, whereas engineers in the workplace are expected to come up with innovative solutions for dilemmas instead of following systematic constructions as they do in undergraduate lab courses. Therefore, most graduates end up lacking the problem-solving skills needed to meet the industry's expectations. Additionally, the standard lab procedures do not allow intergroup collaboration or discussions. This limited the development of teamwork skills needed in the workplace (Elahinia \& Cioca- 
nel, 2008).

Although lab courses are tailored to serve a specific purpose, it has been noted that graduate engineers in the US are not ready for the work field, and they need additional training than the ones they received in lab courses (Warsame, 2017). To illustrate, the American Society for Engineering Education (ASEE) (2012 as cited in Warsame, 2017) argued that even though engineering labs in universities are equipped to meet the requirements of the workplace, the technological advancements made it difficult for lab instructors to teach students how to handle most equipment at work that are frequently updated. In other words, it was observed that engineers are not fully capable of finding solutions to cases presented in the field after graduating from colleges nor able to write lab reports (Duderstadt, 2010 as cited in Warsame, 2017).

Likewise, the engineering students at a private Lebanese university seem to suffer from poor preparation for the workplace. In fact, some of these students complained about their inability to survive well in their internship. The aim of this research was, therefore, to investigate the extent to which the engineering educational program at this private Lebanese university is preparing students for the workplace. The rationale behind this research was to help ensure that the engineering educational program at this university serves its purpose.

This study took place at a small private Lebanese university $\left(54,000 \mathrm{~m}^{2}\right)$ located in Mount Lebanon. The university has four colleges that offer academic courses for both graduate and undergraduate studies. Each college consists of three to four different departments that offer more than twenty accredited programs. The college of engineering is the most populated college in the university; it has about 420 students. Established in 1999, the college of engineering currently offers six different undergraduate engineering programs in Biomedical, Civil, Computer and Communications, Electrical, Mechanical, and Mechatronics Engineering, which are all accredited by the Lebanese Ministry of higher education. The Bachelor of Engineering (BE) degree, provided by each engineering program, encompasses 147 credits. These credits are distributed as follows: General education (30 credits), college requirements (31 credits), and program requirements ( 86 credits). In the general education, students are expected to take communication courses, social sciences, and humanities. In the college and program requirements, students take foundation courses (referred to as theoretical courses in this study) and lab courses. All students are required to complete an 8-week internship to graduate.

\section{Literature Review}

This section is divided into four sub-sections, the first of which depicts some studies regarding the demanded skills in the engineering workplace. The second and third section review research studies on the role of theoretical and lab courses in the workplace respectively. The last section reviews some literature on the role of training programs in the workplace. 


\subsection{Skills Required in the Workplace}

The success of the business industry relies on having engineers equipped with technical skills to deal with workplace challenges (Crumpton-Young, McCauley-Bush, Rabelo, Meza, Ferreras, Rodriguez, \& Kelarestani, 2010). In fact, soft skills are equally important as hands-on skills for the engineers in the workforce (Anastasiu et al., 2017). Employees need specific skills to handle tasks and resolve potential problems. They also need to demonstrate leadership skills to survive in the workplace. More specifically, they need to exhibit communication, teamwork, problem-solving, organizational and decision-making skills (Crumpton-Young et al., 2010).

In more detail, a study that interviewed 213 engineering students and 264 professional engineers at University of Central Florida inquired about the most important skills needed in the workplace. The results of this study concluded that communication, problem-solving, and teamwork skills are the main skills needed in the work field (Crumpton-Young et al., 2010). Another study conducted by The Center for Technical Communication at State University of New York interviewed 208 former students who stated that collaborative skills are the most needed skills in the workplace (Sageev \& Romanowski, 2001). Moreover, according to Chatarajupalli, Venkatswamy, and Aryasri (2010), employers in the workplace target engineers who are good at monitoring, organizing, and designing.

To sum up, the most demanded skills for engineers in the workplace are communication, leadership, teamwork, and problem-solving.

\subsection{Role of Theoretical Courses in the Workplace}

To begin with, the main goal of any engineering program is to prepare students to be able to practice their profession (Feisel \& Rosa, 2005). In fact, Warsame (2017) stated that organizations such as the Accreditation Board for Engineering and Technology (ABET) emphasize the importance of having a strong connection between fundamental courses and the workplace. To ensure such a connection, many colleges added a new section in their curriculum that requires working in groups (ABET, 2014 as cited in Warsame, 2017). Therefore, students working in groups get to enhance skills required in the workplace such as teamwork, leadership, decision-making, and communication (Hansen, 2006). In addition, since graduating engineers should have problem-solving skills to thrive in the workforce, professors are trying to integrate case studies into core courses (Pan, 2014).

\subsection{Role of Lab Courses in the Workplace}

Lab courses that undergraduate engineers take provide students with the necessary skills they need in the workplace (Carberry, Lee, \& Swan, 2013; Feisel \& Rosa, 2005 among others). To illustrate, employers reported that lab courses are crucial for the work field since they teach undergrads to use equipment, handle data, and write reports (Carberry et al., 2013). Due to practical courses, graduat- 
ing engineers are able to excel in the workforce and in their area of expertise since they are now able to design and conduct experiments, interpret data, function in multidisciplinary teams, and formulate engineering problems (Carberry et al., 2013). On a more specific note, Lesková (2013) stated that mechanical engineering graduates who took lab courses gained the skills needed in product design, and they further mastered skills in design optimization whereby they can design a project in cost-effective resources and in a short duration. Those students gained skills in design assembly, design disassembly, and design cost. These are critical skills for any engineer to outshine others in their workplace (Carberry et al., 2013). Leskova (2013) further noted that mechanical engineers that were engaged in hands-on workshops showed innovative thinking and excellent hands-on skills in the workforce.

Furthermore, Feisel and Rosa (2005) stated that graduating engineers are expected to have a smooth transition from their undergraduate programs to the workforce after these engineers complete the required engineering lab courses. In fact, Feisel and Rosa (2005) argue that engineering students should be able to recognize the limitations and the strengths of theoretical models, develop experimental tactics, and draw conclusions from the data collected and analyzed. Furthermore, by following appropriate methodologies, students are able to meet the clients' requirements by designing, building, or assembling systems (Feisel \& Rosa, 2005).

Moreover, lab courses equip students with practical and interpersonal skills that are indispensable for communication in any engineering domain. Carberry et al. (2013) emphasized the importance of engineering laboratories in developing skills needed in the workplace. Those skills include teamwork and citizenship. Lab courses also help students address complex problems and reflect on them. All these skills are traits that employers look for in their prospective employees (Carberry et al., 2013).

\subsection{Role of Training Programs in the Workplace}

Many researchers have agreed that training programs play an important role in the engineering workplace. Miao, Yuan, and Gu (2013) contended that engineering training has a significant role in higher engineering education. More specifically, training programs enhance students' creativity and ability to innovate. They train students to implement knowledge acquired and apply multi-disciplinary knowledge where needed (Miao et al., 2013).

According to Patki and Patki (2016), engineers who are enrolled in training programs learn about the skills, demands, and work ethics of the workplace. They further gain competences in their specialized fields when they are exposed during their training to hands-on workshops that equip them with information not acquired during their undergraduate studies. Furthermore, Dehing (2012) and Shuman et al., (2000) stated that training programs introduce students to their actual profession. During those programs, students are introduced to employability skills that facilitate joining their prospective programs (Dehing, 
2012). Part of this employability is learning how to deal with clients and communicate efficiently in the workplace. According to Patki and Patki (2016), not only do those programs train students to handle tasks responsibly and deal with expert counsellors to build networks, but they also help them gain interpersonal skills such as communication, critical thinking, logical thinking, teamwork, lifelong learning, problem-solving and decision-making skills as potential skills for trained students.

On a further note, Shuman et al. (2000) stated that training and education have a significant impact on the quality and productivity of the work produced by graduates. Furthermore, Garavan and Murphy (2001) stated that training programs help students boost their social skills, practical abilities, and self-confidence.

In nutshell, the engineering educational program consisting of theoretical courses, lab courses, and training program (internship) should help students develop the needed skills, namely communication, leadership, teamwork, and problem-solving skills to meet the demands of the workplace. Thus, it was interesting to see to the extent to which the engineering educational program at this private Lebanese university prepares its students for the workplace.

\section{Research Questions}

To help ensure that the engineering educational program at the university serves its purpose, the following question was addressed in this study: To what extent does the engineering educational program at this Lebanese university prepare its students for the workplace? To answer this question, the following sub-questions were addressed:

1) How do the required theoretical courses at the private Lebanese university help engineering students meet the requirements of the workplace?

2) How do the university lab courses prepare students for the workplace?

3) How does the internship program prepare the university's students for the workplace?

\section{Methodology}

\subsection{Design and Data Collection Methods}

In this study, the researchers employed the mixed-methods design which integrates both qualitative and quantitative data within the same investigation (Morgan, 2014). To exemplify, according to Morgan (2014: p. 34), "the basic premise of this methodology is that such integration permits a more complete and synergistic utilization of data than do separate quantitative and qualitative data collection and analysis". That is why the mixed-methods design was employed in this study to fully understand the research problem. Both qualitative and quantitative data instruments were used. Quantitative data were collected by a 31-question survey whose Cronbach's Alpha was .710. To get deep rich data, six 20-minute semi-structured interviews with 3 graduates and 3 trainees, each 
of whom was of a different major, constituted the qualitative data.

\subsection{Data-Analysis}

The data collected were analyzed both qualitatively and quantitatively. Descriptive analysis of the quantitative data was done through Excel. Thematic analysis, which is the process of classifying qualitative data into themes or patterns (Maguire \& Delahunt, 2017), was used to analyze the collected qualitative data. Then the findings of both types of data were triangulated to ensure more credibility and validity of the findings.

\subsection{Participants}

In order to collect primary data for this study, the researchers surveyed a purposive sample of 100 engineering trainees and graduates (51 trainees and 49 graduates), who were guaranteed confidentiality and anonymity. The questionnaires were distributed in two ways: by hand to the trainee participants who were on campus and through email to the graduates who left the university and joined the workforce. The return rate was $100 \%$. Additionally, all the participants were asked to indicate their willingness to be interviewed, and out of those who did, 6 respondents ( 3 trainees and 3 graduates) were chosen purposively. The respondents were of different majors: Electrical engineering (5), computer and communication engineering (15), biomedical engineering (13), mechanical engineering (14), mechatronics engineering (18), and civil and environmental engineering (35). The small number of electrical engineering participants and the big number of civil engineering participants could be justified as the former is the least populated and the latter is the most populated in the university. Furthermore, the participants had their training in the following workplaces: Khatib and Alami, Alfa, Touch Telecom, Abed el Wahide Shehab, Saudi Oger, Bassoul-Heneine, Jubaili Bros, Rafik Hariri University Hospital, and Middle East Airlines.

\section{Findings and Discussion}

The findings, which were in line with the literature, are presented as themes derived from the analyses of the collected data. These themes represented the participants' perceptions of the extent to which their theoretical courses, lab courses, and internships prepared them to meet the demands of the workplace.

\subsection{Role of Theoretical Courses in the Workplace}

\subsubsection{Participants' Perceptions of the Theoretical Courses}

The data collected showed that the majority of the respondents reported that theoretical courses did not help them survive in the workplace. In fact, only $8 \%$ of the participants found that theoretical courses were fully helpful in preparing them to practice their profession (See Figure 1).

The qualitative data helped get better understanding of the above percentages. Participants who mentioned that theoretical courses improved their workplace 


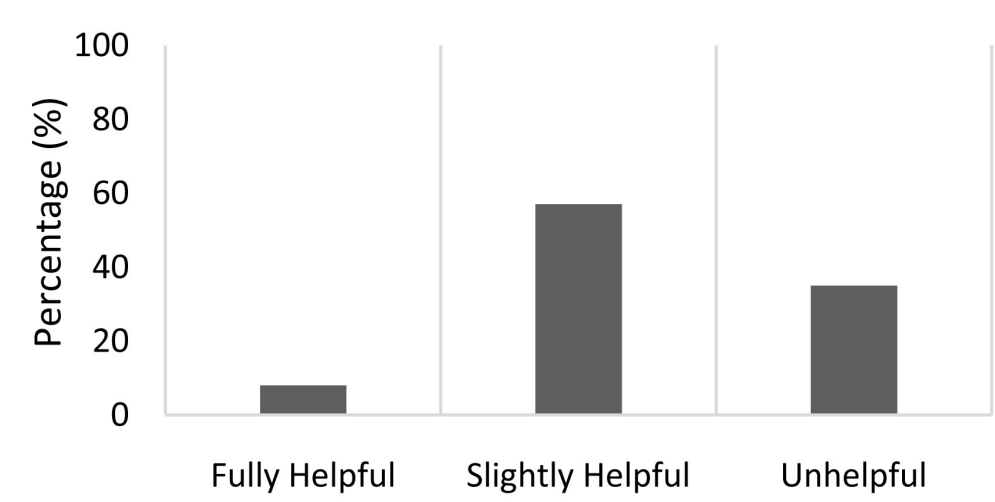

Figure 1. Participants' perceptions of theoretical courses.

experience believed that the teaching methods followed by a few instructors helped them excel in the workplace. One respondent explained, "Instructors taught us how to analyze problems, see them from different perspectives, try to distinguish the causes, and finally suggest a solution". The participants that selected the slightly helpful category felt that theoretical courses taught them some information used in the workplace. Another participant said, "Only a few instructors use teaching tactics that prepare us for the workplace".

However, those who chose the "unhelpful" category thought that the information taken in theoretical courses was not used in the workplace. They believed that theoretical courses included general information on each topic unlike what is required in the workplace. A graduate reported, "The educational system is very different from the work domain and topics taken in the courses are way too general. In fact, when exposed to the workplace, you will need deeper understanding of the subjects to be able to tackle the tasks given".

Another participant said, "Major courses such as Manufacturing and Control Applications that teach control, power panel design, and logic controllers are not given in the electrical engineering program at the university".

To sum up, it seems that theoretical courses at this university are not sufficiently preparing engineering students for the workplace, which is in line with Warsame (2017).

\subsubsection{Theoretical Courses and Communication Skills}

Based on the quantitative data, it was observed that theoretical courses did not play a major role in enhancing students' communication skills. In fact, only $16 \%$ of the participants agreed that theoretical courses helped them develop communication skills (See Figure 2).

Analysis of the qualitative data provided deeper understanding of the participants' answers. The participants that selected the "strongly disagree" or "disagree" category stated that the courses given at the university are not enough to enhance their communication skills. "I felt that all I did during class was listening to the teacher talk; there was no room for communication during sessions", one participant said. 


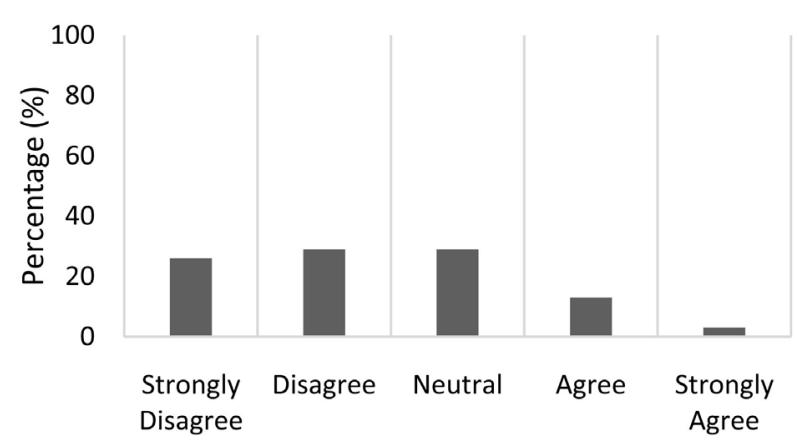

Figure 2. Participants' attitudes towards the role of theoretical courses in enhancing communication skills.

Those who selected the "strongly agree" and "agree" categories mainly said the general education courses helped them gain communication skills. One explained, "Communication skills are mainly gained from social science electives". She added, "We were encouraged to express our ideas in front of people." Although this participant referred to social science electives, most probably she could be referring to English communication courses and Humanities too, but students tend to refer to all these courses as social sciences. Other participants thought that mandatory projects developed their communication skills, "Working in group projects then presenting them in front of classmates taught us how we could explain and present ideas".

\subsubsection{Theoretical Courses and Leadership Skills}

Based on the collected quantitative data, most respondents were of the opinion that they lacked the leadership skills needed in the workplace. To illustrate, only $23 \%$ of the participants believed that they had the required leadership skills in the workplace (see Figure 3).

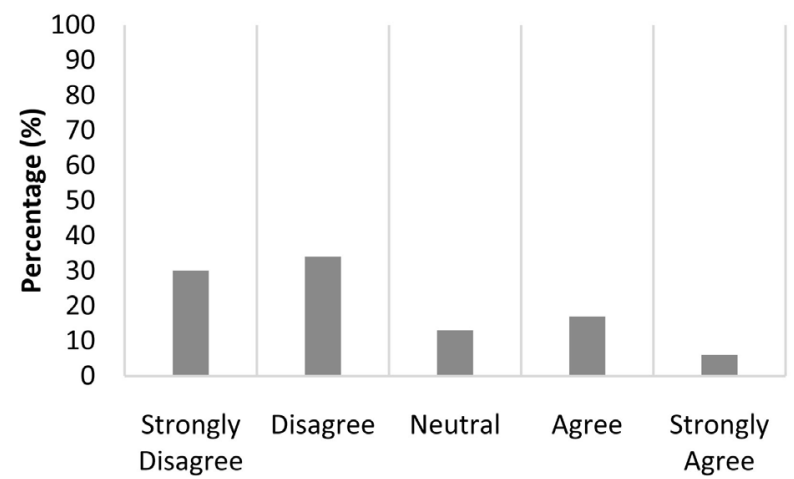

Figure 3. Participants' attitudes towards the role of theoretical courses in enhancing leadership skills.

The qualitative data, which were in line with the quantitative data, gave better understanding of the participants' answers. One graduate mentioned, "While working on a team project during my training, I wasn't able to step up to be the leader since I felt that I did not possess the necessary skills". Another stated, "I 
felt that I wasn't an effective leader whenever I was working on a project". Therefore, the majority of these participants felt that they lacked the leadership skills needed in the workplace, which is in line with Ambrose's (2013 cited in Warsame, 2017).

To conclude, although a few instructors and some courses could help some of the participants develop communication and problem-solving skills, the majority of the participants were of the opinion that the theoretical courses didn't prepare them well for the workplace.

\subsection{Role of Lab Courses in the Workplace}

\subsubsection{Lab Courses and Teamwork Skills}

Based on the quantitative data, the participants reported that the lab courses did not help them develop the teamwork skills needed in the workplace. In fact, $60 \%$ of the participants were of this opinion (See Figure 4).

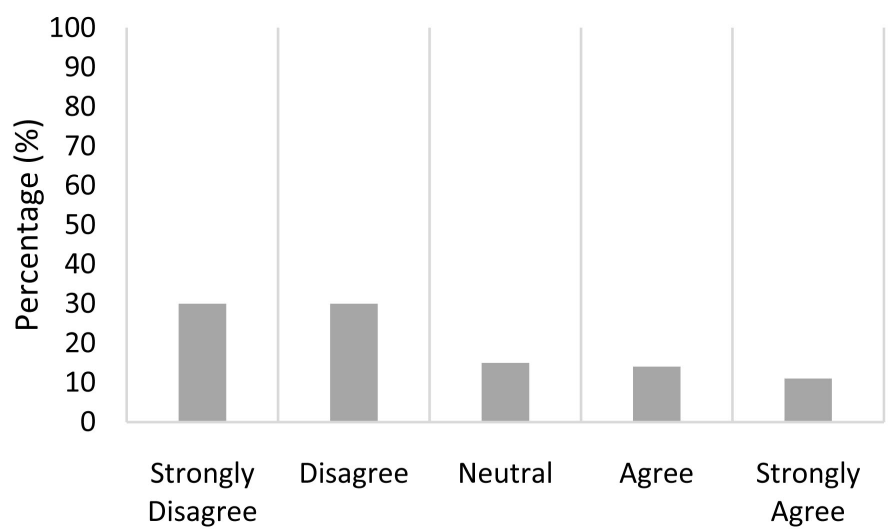

Figure 4. Participants' attitudes towards the role of labs in developing teamwork skills.

The data derived from the interviews reviewed some reasons behind the respondents' attitudes. To exemplify, most of the participants felt that when they entered the workplace, they lacked teamwork skills. One of the interviewees stated, "I felt that I lacked the teamwork skills needed to work with employees around me". In addition, another participant mentioned, "I learned how to be a team player when I had to work with other engineers to get a task done in the workplace".

On the other hand, only a few participants stated that they possessed the needed teamwork skills to thrive in everyday work; "The labs enhanced my teamwork skills since we had to work in pairs during lab sessions". Another said, "Working with individuals of different knowledge levels in the university taught me various collaborative skills".

Hence, based on the findings, the majority of the participants believed that they need to improve their teamwork skills. This same skill was also stressed by Warsame (2017).

\subsubsection{Lab Courses and Problem-Solving Skills}

The majority of the participants thought that they were not completely able to 
find solutions when facing problems in the workplace. In fact, only $28 \%$ of the participants thought otherwise (See Figure 5).

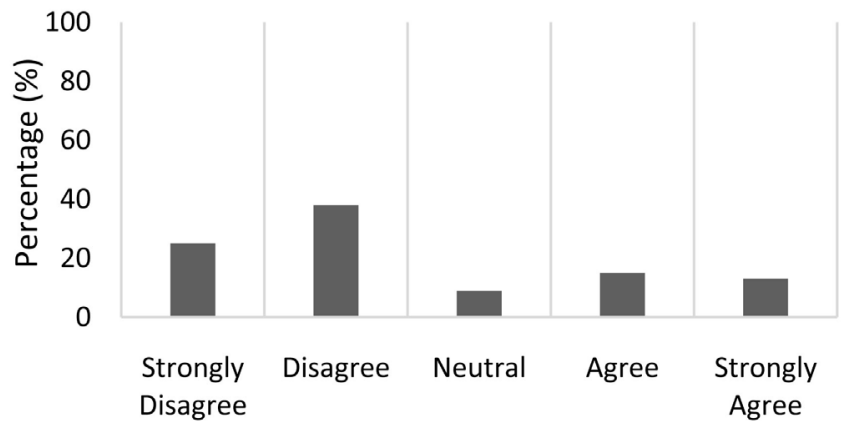

Figure 5. Participants' perceptions of their ability to find solutions in the workplace.

The data derived from the interviews helped get deeper understanding of the engineers' perceptions. To illustrate, most of the participants stated that they were taught in lab courses how to follow a task rather than solve a problem. An interviewee said, "We were given a set of instructions to follow in the lab, not a problem to solve".

\subsubsection{Handling Equipment}

The respondents in the questionnaires reported that lab courses did not much help them thrive in the workplace. To exemplify, only $22 \%$ of the participants believed that they were able to handle equipment. Figure 6 gives more details regarding the participants' perceptions of their ability to handle equipment in the workplace.

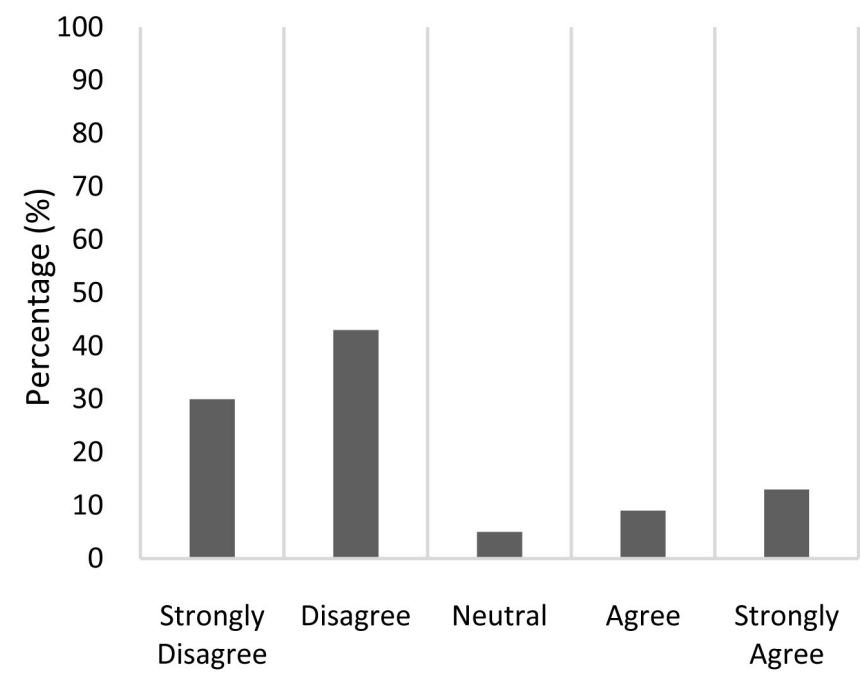

Figure 6. Participants' attitudes towards the role of labs in helping them handle equipment in the workplace.

The qualitative data provided further insights into the participants' perceptions of lab courses. The few, who were of the opinion that lab courses were 
helpful, thought that they were exposed to similar ideas in these courses. For example, a trainee mentioned, "In the airport, I had to measure voltage, resistance, and current, which is a skill taught in most of the labs".

However, the majority were of the opinion that lab courses were unhelpful. For instance, one graduate stated, "You could say that only $40 \%$ percent of the tasks assigned during my internship was taken in the lab courses". Besides, a graduate confirmed he had to learn how to use new tools on his own not during lab courses, "I learned how to handle a drill and a welding machine on my own, even though such a skill could have been easily taught in lab courses". Furthermore, one participant reported, "Manufacturing applications such as power panels design and programmable logic controllers, which are a major part of any electrical job, are not given in any lab".

\subsubsection{Wring Reports}

Based on the findings, about half of the respondents stated that they were able to write reports in the workplace. In fact, $48 \%$ of the participants believed that they were able to produce reports in the workplace (See Figure 7).

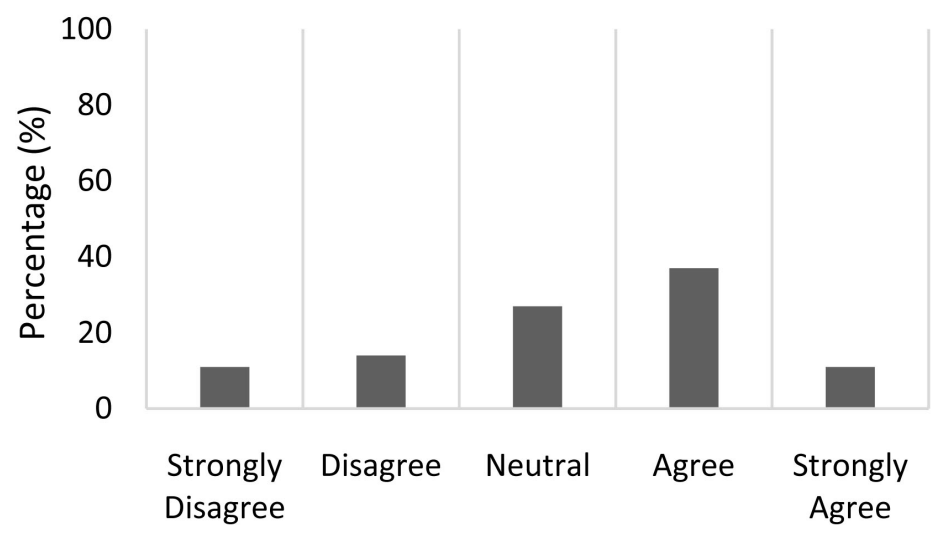

Figure 7. Participants' perceptions of their ability to write reports in the workplace.

The qualitative data were in line with the quantitative data. One participant reported, "I was able to write reports by the end of each task".

To sum up, it seems that lab courses are not fully preparing engineering students to handle the equipment found in the workplace. In fact, this is also in line with ASEE (2012 as cited in Warsame, 2017). However, half of the participants perceived that their communication skills developed in the general educational course helped them write reports which is one of the skills highly demanded in the workplace.

\subsection{Role of Internship in the Workplace}

\subsubsection{Participants' Attitudes towards the Internship Experience}

Based on the data collected, the respondents had a positive attitude towards their internship experience. In fact, $70 \%$ of the participants rated their training experience between excellent, very good, and good (See Figure 8). 


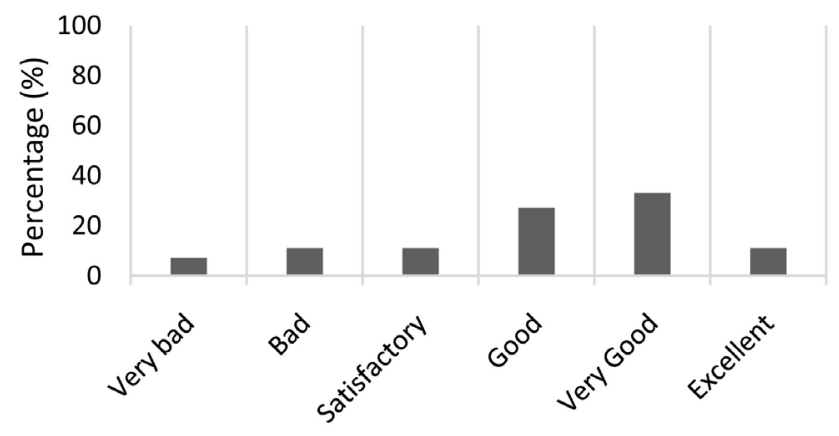

Figure 8. Attitudes of the respondents towards their internship.

The qualitative data were in line with the quantitative data. One participant reported, "I was able to write reports by the end of each task".

To sum up, it seems that lab courses are not fully preparing engineering students to handle the equipment found in the workplace. In fact, this is also in line with ASEE (2012 as cited in Warsame, 2017). However, half of the participants perceived that their communication skills developed in the general educational course helped them write reports which is one of the skills highly demanded in the workplace.

Furthermore, the participants described their internship experience mostly as helpful (58\%) and interesting (20\%) (See Figure 9).

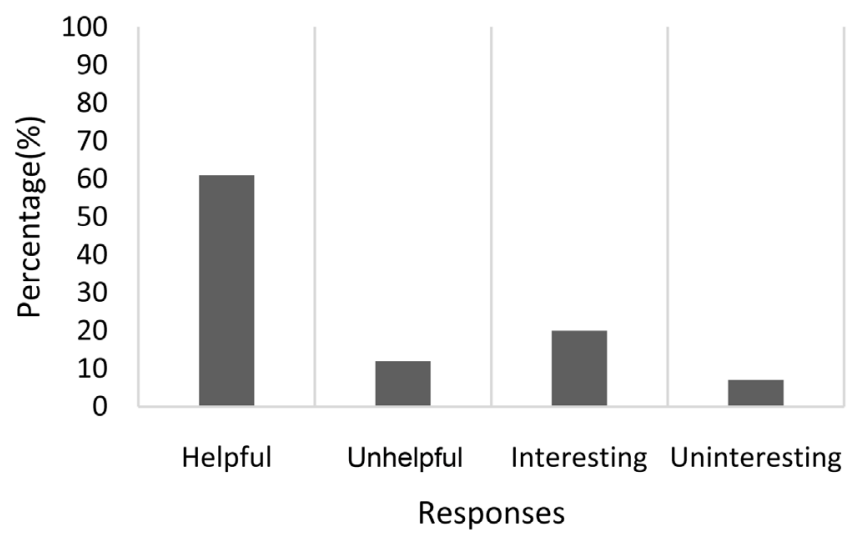

Figure 9. Respondents' perceptions of their internship experiences.

The qualitative data helped get deeper understanding of the participants' attitudes. To illustrate, most of the participants described their experience as helpful due to several reasons, the first of which was learning new information; one wrote "I learned the tasks of a telecom engineer and his role in facilitating people's lives and improving the mobile communication field". Another reason was that they gained practical skills that weren't acquired during their undergraduate studies as stated by one participant, "I learned how to do preventive and corrective maintenance for equipment, how an MRI, ventilator, and dialysis machine functions". They also found that their soft skills, which are needed in the workplace, were enhanced; one respondent reported, "It taught me how to 
contact companies to do preventive maintenance and how the hierarchy of an organization should be respected".

Only twelve percent of the participants rated their experience as unhelpful. One mechanical engineer said that his internship was not related to his major, "Even though the company I worked at was specialized in manufacturing motors, three quarters of the work I had to do was electrical". Another participant who had his internship in Saudi Oger stated that the company he worked at was outdated and did not add to his previous knowledge and skills, "The company I did my training at still uses floppy disks to upload data". Some of the interviewees thought that their experience was unhelpful since they didn't have many training options to choose from. One reported that, "Civil engineers can work in different fields such as construction, ready mix, environmental and others; however, the university offers only two of these options".

Furthermore, less than half of the participants (46\%) found that their internship duration was short, whereas, $17 \%$ of the participants thought it was long (See Figure 10). It seems that the type of work they did in their internship affected their perceptions as explained by the participants. Indeed, one of the respondents said, "I felt that I was doing the same job over and over again, it kind of felt monotonous and boring".

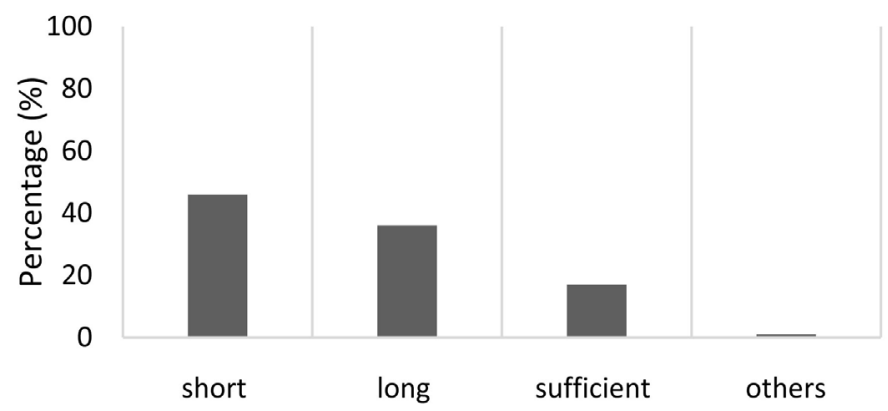

Figure 10. Respondents' perceptions of the internship duration.

The respondents who were in favor of elongating the internship provided several reasons for their opinion. One of the participants felt that increasing the duration of the internship would increase the opportunity of finding a job, "I believe that having a 3-month training program would increase the chances of being accepted in any company". Another explained, "Increasing the number of training programs required by students expands their knowledge and competences in the workplace". Even the respondent that selected the others category was with extending the duration of the internship, "The internship should be extended to three months".

Some of the participants (36\%) were satisfied with the current duration of the internship; one of the interviewees explained, "I felt that the duration of internship was just right; I went five days a week from seven till five for a month and a half and that was enough to add to my expertise".

To sum up, most of the graduates and trainees seem to have a positive attitude 
towards their internship, for they thought it was a helpful experience due to various reasons. However, most of them believed that the program could be improved by extending its duration and adding further options for students to select from (c.f. Miao et al., 2013).

\subsubsection{Perceived Benefits of Internship}

Based on the collected quantitative data, the respondents reported that the internship had a positive impact on helping them develop important skills for the workplace. In fact, the most reported benefits were handling modern engineering tools (55\%), enhancing problem-solving skills (55\%), improving social and interpersonal skills (54\%), boosting their communication skills (54\%), and introducing them to the new profession (50\%) (See Table 1).

Table 1. Respondents' perceptions of internship benefits.

\begin{tabular}{cc}
\hline Handling modern engineering tools & $55 \%$ \\
Enhancing problem-solving skills & $55 \%$ \\
Improve social and interpersonal skills & $54 \%$ \\
Boosting their communication skills & $54 \%$ \\
Introducing to the new profession & $50 \%$ \\
\hline
\end{tabular}

Analysis of the qualitative data helped get deeper understanding of the above percentages. Participants stated that during their internship they learned how to handle new equipment and software; "I learned about new medical equipment that wasn't taught in class", "I learned how to work on new software".

A lot of the participants have also referred to how their internship improved their interpersonal and social skills as well as communication skills; one participant reported, "My internship mainly taught me how to communicate with workers, supervisors, and clients".

Other participants talked about how their internship helped them know more about their major. One participant said, "During the internship, I found a deeper meaning and understanding to my major".

Although most of the participants felt that their problem-solving skills had not been developed before their internship, they believed that their internship helped them improve these demanded skills. In fact, one of the participants said, "When I worked in the maintenance department, I was taught how to identify errors in machines".

To sum up, the participants seemed to be satisfied with their internship experience due to the advantages it offered. This echoes with what was stated in the literature presented by Dehing (2012).

\section{Conclusion and Recommendations}

The aim of this research was to investigate the extent to which the engineering educational program at a private Lebanese university is preparing students to the workplace. Employing a mixed-methods design, the researchers surveyed 100 
engineering participants purposively sampled and interviewed 3 graduates and 3 trainees. The collected data which were analyzed quantitatively as well as qualitatively were triangulated and a lot of commonalities were detected. It was found that the theoretical and lab courses were not so effective in helping students develop the demanded skills for the workplace, namely teamwork, communication and problem-solving skills. However, most of the respondents had a positive attitude towards their internship experience due to its effectiveness in preparing them for the workplace and the positive impact it had on their careers. Based on the aforementioned findings, it seems that the engineering educational program at this private university does not well prepare its graduates for the workplace.

Although other engineering graduates and trainees from various Lebanese universities in most workforce may complain about the same problem, there is no attempt to generalize the findings beyond this private Lebanese university due to the non-probability sample selected only from this university.

To better prepare graduates for the workplace, the researchers suggest two types of recommendations that are likely to improve the engineering educational program at this private Lebanese university: one at the level of the classroom and the other at the level of the university. At the classroom level, the researchers recommend that instructors lead more engaging student-centered classes where students can have an active role in class discussions instead of being passive learners and that instructors include real-life case studies, based on incidents that happen in the workplace to enhance students' problem-solving skills. Moreover, the researchers recommend adding more team projects, in both theoretical and lab courses to develop students' teamwork and interpersonal skills.

At the university level, the researchers suggest that the university adds up-to-date equipment and software in lab courses to expose the engineering students to machines that they will most likely encounter in the workplace. In addition, they recommend adding a mandatory public speaking course in order to enhance students' communication and leadership skills. To provide students with internships that match with their specialization, the researchers suggest adding more company options of different subspecialties for students to choose from. They also recommend elongating the internship experience to three months to help students gain more hands-on experience in their fields.

\section{Conflicts of Interest}

The authors declare no conflicts of interest regarding the publication of this paper.

\section{References}

Anastasiu, L., Anastasiu, A., Dumitran, M., Crizboi, C., Holmaghi, A., \& Roman, M. N. (2017). How to Align the University Curricula with the Market Demands by Developing Employability Skills in the Civil Engineering Sector. Education Sciences, 7, 74. https://doi.org/10.3390/educsci7030074 
Carberry, A. R., Lee, H., \& Swan, C. W. (2013). Student Perceptions of Engineering Service Experiences as a Source of Learning Technical and Professional Skills. International Journal for Service Learning in Engineering, 8, 1.

https://doi.org/10.24908/ijsle.v8i1.4545

https://search.proquest.com/docview/1368765935?accountid=158790

Chatarajupalli, S., Venkatswamy, G., \& Aryasri, A. (2010). Leveraging e-Learning for Enhancing Employability of Students. In 2010 Developments in E-systems Engineering (pp. 107-112). London: IEEE.

https://doi.org/10.1109/DeSE.2010.25

Crumpton-Young, L., McCauley-Bush, P., Rabelo, L., Meza, K., Ferreras, A., Rodriguez, B., \& Kelarestani, M. (2010). Engineering Leadership Development Programs a Look at What Is Needed and What Is Being Done. Journal of STEM Education: Innovations and Research, 11, 10-21.

https://search.proquest.com/docview/366386001?accountid=158790

Dehing, F. (2012). Preparing Students for Workplace Learning in Higher Engineering Education (pp. 1-161). Dutch: Eindhoven University of Technology.

Elahinia, M. H., \& Ciocanel, C. (2008). A Problem-Solving Approach for Teaching Engineering Laboratories. International Journal of Mechanical Engineering Education, 36, 140-159. https://search.proquest.com/docview/200138149? accountid=158790 https://doi.org/10.7227/IJMEE.36.2.5

Feisel, L. D., \& Rosa, A. J. (2005). The Role of the Laboratory in Undergraduate Engineering Education. Journal of Engineering Education, 94, 121-130.

https://doi.org/10.1002/j.2168-9830.2005.tb00833.x https://search.proquest.com/docview/217947502?accountid=158790

Garavan, T. N., \& Murphy, C. (2001). The Internship Erative Education Process and Organisational Socialisation: A Qualitative Study of Student Perceptions of Its Effectiveness. Education \& Training, 43, 281-302. https://doi.org/10.1108/EUM0000000005750 https://search.proquest.com/docview/237068949?accountid $=158790$

Hansen, R. S. (2006). Benefits and Problems with Student Teams: Suggestions for Improving Team Projects. Journal of Education for Business, 82, 11-19. https://doi.org/10.3200/JOEB.82.1.11-19

Lesková, A. (2013). Laboratory Training to Support Automotive Engineering Skills. Journal of Technology and Information Education, 5, 26-31. https://doi.org/10.5507/jtie.2013.030 https://search.proquest.com/docview/1561987756?accountid $=158790$

Maguire, M., \& Delahunt, B. (2017). Doing a Thematic Analysis: A Practical, Step-by-Step Guide. http://ojs.aishe.org/index.php/aishe-j/article/viewFile/335/553

Miao, X. W., Yuan, G. F., \& Gu, Y. Q. (2013). Creation and Practice of Teaching System on Engineering Training for Training Distinguished Engineers. Applied Mechanics and Materials, 397-400, 2713-2717. https://doi.org/10.4028/www.scientific.net/AMM.397-400.2713

Morgan, D. L. (2014). Integrating Qualitative and Quantitative Methods: A Pragmatic Approach. Thousand Oaks, CA: Sage Publications. https://doi.org/10.4135/9781544304533

Pan, R. (2014). Engineering Students' Experiences and Perceptions of Workplace Problem Solving (pp. 13-148). Doctoral Dissertation, West Lafayette: Purdue University.

Patki, V., \& Patki, M. (2016). Importance of Industry Training for Engineering Undergraduate Students-Case Study. International Journal of Emerging Trends \& Technology in Computer Science, 4, 164-167. https://doi.org/10.18411/d-2016-154 
Regev, G., Gause, D. C., \& Wegmann, A. (2008). Requirements Engineering Education in the 21st Century, An Experiential Learning Approach. In 2008 16th IEEE International Requirements Engineering Conference (pp. 85-94). Catalunya: IEEE . https://doi.org/10.1109/RE.2008.28

Sageev, P., \& Romanowski, C. J. (2001). A Message from Recent Engineering Graduates in the Workplace: Results of a Survey on Technical Communication Skills. Journal of Engineering Education, 90, 685. https://doi.org/10.1002/j.2168-9830.2001.tb00660.x https://search.proquest.com/docview/217957692?accountid=158790

Shuman, L. J., Delaney, C., Wolfe, H., Scalise, A., Besterfield-Sacre, M., \& Tung-Chun, H. (2000). Pre-Job Training and the Earnings of High-Tech Employees in Taiwan. Innovations in Education and Training International, 37, 10.

https://doi.org/10.1080/135580000362034

https://search.proquest.com/docview/210681995?accountid $=158790$

Warsame, A. F. (2017). The Gap between Engineering Education and Postgraduate Preparedness (Order No. 10634462).

https://search.proquest.com/docview/1964262359?accountid=158790 